\title{
Interdecadal variations of the East Asian winter surface air temperature and possible causes
}

\author{
YANG LiuNi \& WU BingYi* \\ Chinese Academy of Meteorological Sciences, Beijing 100081, China
}

Received December 17, 2012; accepted April 26, 2013; published online June 20, 2013

\begin{abstract}
Using the NCEP/NCAR and JRA-25 monthly analysis data from 1979 to 2011, this paper analyzes the interdecadal variations of winter (Dec.-Feb.) mean surface air temperature (SAT) over East Asia by means of the empirical orthogonal function (EOF) analysis method. Two dominant modes were extracted, with the leading mode basically depicting a sign consistent SAT variation and the second mode describing a meridional dipole structure between the northern and southern parts of East Asia. These two modes can explain more than $60 \%$ of the variance. The leading mode is closely related to the intensity of Siberian high and the East Asian winter monsoon. The second mode exhibits a notable interdecadal shift in the late 1990s, with a turning point around 1996/1997. Winter SAT in the northern (southern) part of East Asia tends to be cooler (warmer) since the late 1990. Winter sea level pressure (SLP) differences between 1997-2011 and 1979-1996 show negative (positive) anomalies over southern (northern) Eurasia. At 500-hPa, an anomalous blocking high occurs over northern Eurasia, while a cyclone anomaly appears over northern East Asia. In addition, the upper-level East Asian jet stream tends to shift northward and become stronger after the late 1990. Indeed, the interdecadal shift of winter SAT over East Asia is dynamical consistent with changes of the large-scale atmospheric circulation in the late 1990s. The result indicates that previous autumn sea surface temperature (SST) in the North Atlantic Ocean, the Northern Indian Ocean and the western North Pacific Ocean, as well as sea ice concentration (SIC) in the northern Eurasia marginal seas and the Beaufort Sea also experienced obvious changes in the late 1990s. In particular, the interdecadal shifts of both SST in the North Atlantic Ocean and SIC in the Arctic Ocean and its marginal seas are well coherent with that of the winter SAT over East Asia. The results indicate that the interdecadal shift of East Asian winter SAT may be related to changes in the North Atlantic SST and the Arctic SIC in the late 1990s.
\end{abstract}

winter surface air temperature (SAT), interdecadal shift, sea surface temperature (SST), sea ice concentration (SIC)

Citation: $\quad$ Yang L N, Wu B Y. Interdecadal variations of the East Asian winter surface air temperature and possible causes. Chin Sci Bull, 2013, 58: 3969-3977, doi: 10.1007/s11434-013-5911-2

Previous studies demonstrated that there are many factors to affect East Asian winter surface air temperature (SAT) variations, such as atmospheric circulation, sea surface temperature (SST), snow cover and Arctic sea ice concentration (SIC), etc. Thus mechanisms for SAT variations are complicated [1-4]. To better understand possible cause-effect associations and seek potential predictors for winter SAT variability, it is necessary to investigate dominant features of its variability in global warming environment.

In fact, interannual variations of winter SAT over East

*Corresponding author (email: wby@ cams.cma.gov.cn)
Asia and their causes have been investigated extensively. Guo [5] pointed out that East Asian winter SAT was directly affected by the East Asian winter monsoon. Ding [6] suggested that the strength and location of winter Siberian high (SH) had substantial impacts on winter SAT. Mao et al. [7] indicated that the East Asian winter SAT would be higher (lower) than the normal in association with strengthened (weakened) westerlies. Additionally, Arctic Oscillation (AO), North Pacific Oscillation, North Atlantic Oscillation (NAO) and Eurasian wave-train pattern also influence SAT [8-12]. In general, atmospheric circulation anomalies are intimately related to various kinds of external forcing factors. For 
instance, SST anomalies over the Pacific Ocean, the Indian Ocean and the Atlantic Ocean have significant impact on the East Asian winter monsoon and SAT [2,13,14]. Eurasian snow cover anomalies can directly influence the East Asian winter SAT [15]. Besides, there is a close link between the Arctic SIC anomalies and the East Asian winter SAT [16-18].

Recently, lots of research have analyzed the long-term variations of East Asian winter SAT, indicating that the SAT had a notable interdecadal shift in the late 1970s, and increased markedly after that [19,20]. Many studies, from different perspectives, discussed the physical causes of the interdecadal variations in winter SAT over East Asia. And they stated that the East Asian winter SAT variability had relations with interdecadal variations of many other meteorological elements in the climate system, such as sea level pressure (SLP) over the North Pacific Ocean [21], AO and North Atlantic Oscillation (NAO) [22,23], the Northern Hemisphere winter Hadley Circulation [24], westerly circulation in winter [25], East Asian winter monsoon [26], SST over the Pacific Ocean [27], etc. In addition, the greenhouse effect, solar activity, volcanic activity and human activities may contribute to the interdecadal variation of the East Asian winter SAT in the late 1970s as well [28,29].

As mentioned above, the interdecadal variation of East Asian winter SAT in the late 1970s and its possible causes have been discussed extensively. On the basis of previous researches, this paper will aim to investigate interdecadal variations of the East Asian winter SAT for the period of 1979- 2011. To more clearly reveal the possible reasons for the interdecadal shift of East Asian winter SAT, we further analyze anomalies of atmospheric circulation and external forcing in this study.

\section{Data and methods}

The data used in this study include (1) the monthly mean SAT, SLP, 500-hPa geopotential height and 200-hPa zonal wind field from 1979 to 2011, which were obtained from the National Center for Environmental Prediction and the National Center for Atmospheric Research (NCEP/NCAR) reanalysis I datasets [30]; (2) the monthly mean SIC and SST dataset $\left(1^{\circ} \times 1^{\circ}\right)$ for the period of 1979-2011, obtained from the British Atmospheric Data Centre (BADC, http:// www.metoffice.gov.uk/hadobs/hadisst/data/download.html); and (3) the monthly mean SAT from 1979 to 2011, obtained from Japanese 25-year reanalysis (JRA-25) datasets (http://ds. data.jma.go.jp/gmd/jra/download/data/MonthFinal/anl_p25/) [31]. In this paper, winter season is from December to February, and autumn season is from September to November. The intensity of SH is defined as averaged winter SLP in the domain of $\left(40^{\circ}-60^{\circ} \mathrm{N}, 80^{\circ}-120^{\circ} \mathrm{E}\right)$ [32]. In addition, the global climate system had an obvious interdecadal shift in the late 1970s [19,20], and meanwhile, the Arctic SIC dataset assimilated satellite data after 1979 [33]. Moreover, much of the previous research pointed out that the NCEP/ NCAR reanalysis I and JRA-25 data were more applicable after 1979 [34]. Thus, the study period was chosen from 1979 to 2011 in this paper.

The common statistical techniques such as composite analysis, regression analysis and empirical orthogonal function (EOF) are employed in this study. And the abrupt change detection methods including moving $t$-test and Mann-Kendall $(\mathrm{M}-\mathrm{K})$ test are applied as well.

\section{The main variations of East Asian winter SAT}

East Asia is located in the southeastern area of Eurasia, with complex and diverse terrain, which borders on the Pacific Ocean in the east, and close to the southwest of the world's largest plateau named the Qinghai-Tibet Plateau. The unique geographical features of East Asia result in its particular climate characteristics, and make this area one of the most severe and complex climate variability areas in the world [35]. In order to analyze dominant modes of the East Asian winter SAT variability, an EOF analysis is applied to winter monthly mean SAT in the domain $90^{\circ}-140^{\circ} \mathrm{E}, 20^{\circ}-50^{\circ} \mathrm{N}$ during the period of 1979-2011. Variance contribution rates of the first two modes are $42.03 \%$ and $18.29 \%$, respectively. And they can be well discriminated according to the criterion proposed by North [36].

The spatial distribution of the leading mode (EOF1) of the East Asian winter SAT, and its corresponding time series (PC1) is shown in Figure 1. It can be seen that the spatial distribution of EOF1 is characterized by positive SAT anomalies in most parts of East Asia except the southwest region, indicating consistent warming or cooling in winter. Among that, areas exhibiting the largest SAT variations are mainly located in North China and its coastal regions (Figure 1(a)). The PC1 presents a characteristic of remarkable interdecadal variation shown in Figure 1(b), that is, negative phases prevailed before the mid 1980s, followed by positive phases from the mid 1980s to the beginning of 21st century, and then turned to negative phases with a downward trend. These results imply that the East Asian winter SAT is cooling before the mid 1980s, and turns to be warming from the mid 1980 s to the early 21 st century, then begins to decrease, relatively. Further analysis indicates that PC1 is significantly correlated with the winter SH $(r=-0.81$, the correlation coefficient is -0.84 after removing their trends) (not shown). In addition, to explore the winter atmospheric circulation anomalies associated with the interannual variation of East Asian winter SAT, a linear regression analysis is performed on the de-trended PC1 (not shown). It is evident that when PC1 is low, the associated circulation anomalies favor cold air breaking out southward from high latitudes, leading to negative SAT anomalies over the mid-high latitudes of East Asia. Namely, the positive (negative) phases 

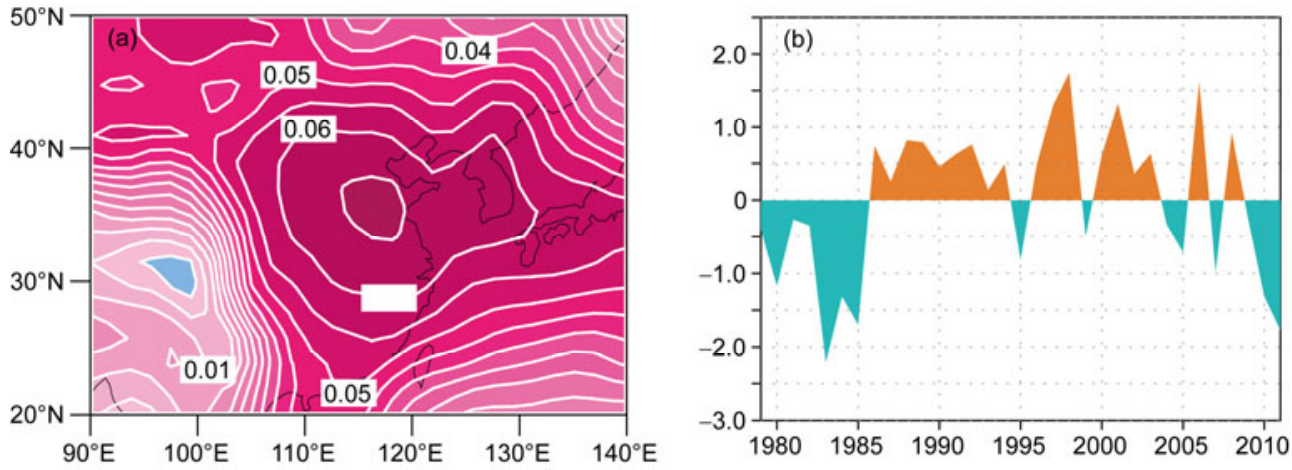

Figure 1 The spatial distribution (a) and standardized time series (b) of the leading mode of East Asian winter SAT derived from NCEP/NCAR reanalysis for 1979-2011.

of PC1 correspond to the positive (negative) SAT anomalies over the mid-high latitudes of East Asia. The above results consistently show that EOF1 is closely related to the strength of $\mathrm{SH}$ and the East Asian winter monsoon system, which agree well with the previous studies [5,18,37].

Since many previous studies have investigated the leading mode (EOF1) of East Asian winter SAT variability and its possible mechanism [18-20], we will mainly aim to discuss the second mode (EOF2). As is shown in Figure 2(a), the spatial distribution of EOF2 presents a north-south opposing variation, indicating that when SAT in northern part of East Asia is cold (warm) anomaly, and the opposite SAT anomaly is observed in southern part of East Asia. The corresponding time series (PC2) demonstrates a noticeable interdecadal variability, with change of sign from negative to positive in the late 1990s, as shown in Figure 2(b). It is evident that negative phases prevailed during 1979-1996 (the mean value is -0.66) and followed by positive phases since 1997 (the mean value is 0.79 ). In order to detect the climate transition of East Asian winter SAT (EOF2) in the late 1990s, a cumulative deviation time series and the moving $t$-test method are performed on the PC2 (Figure 3(a)-(b)). These analysis results show that the transition of PC2 occurred at around 1996/1997. The Mann-Kendall test is also applied to the PC2, further confirming that " $1996 / 1997$ " is a turning point at the $95 \%$ significant test (not shown). It implies that before 1997 positive (negative) SAT anomalies occupied the northern (southern) part of East Asia, and then were replaced
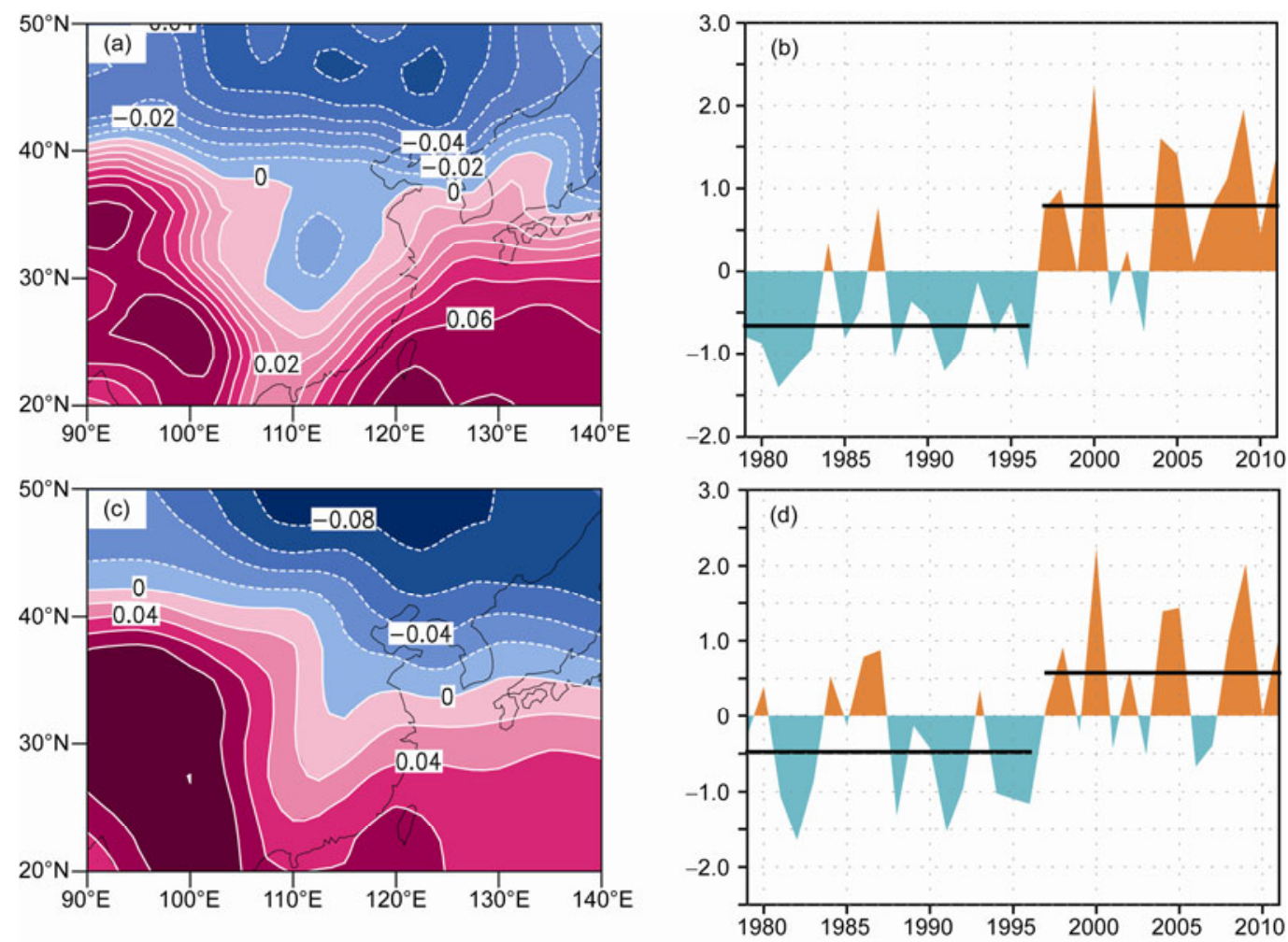

Figure 2 (a)-(b) Same as in Figure 1, but for the second mode; (c)-(d) as in (a)-(b), but for the results derived from the JRA-25 reanalysis data. 

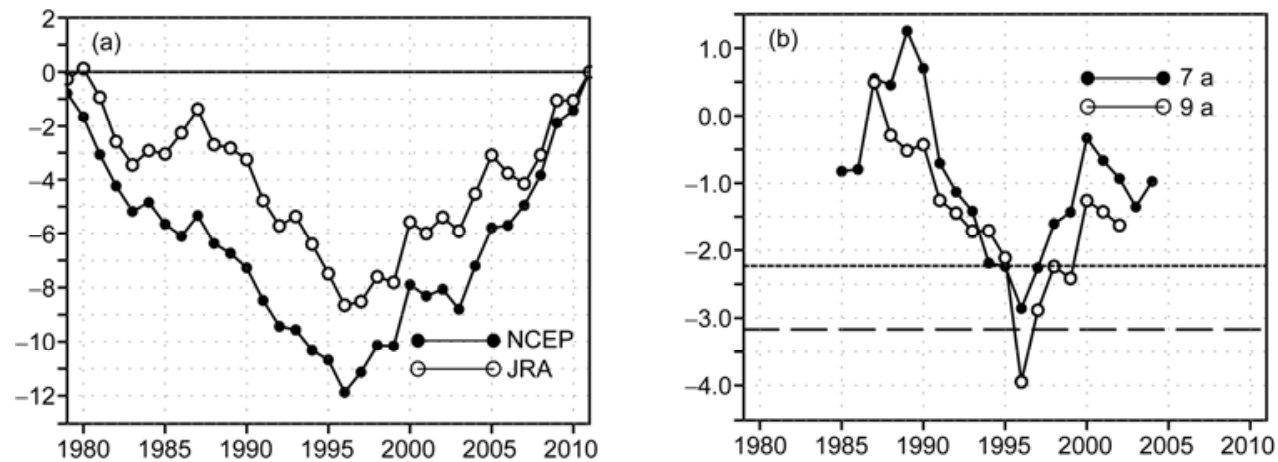

Figure 3 (a) Accumulative anomaly curve and (b) moving $t$-test of the time series of the second mode of East Asian winter surface air temperature for 1979-2011. Dots and circles in (a) represent the NCEP/NCAR and JRA-25 reanalysis data, respectively. Dots and circles in (b) represent 7- and 9-year running means, and the short and long dashed lines denote significance exceeding the $95 \%$ and $99 \%$ significant tests, respectively.

by negative (positive) SAT anomalies since 1997. Similar interdecadal variation analysis (Figure 2(c)-(d)) and turning point (Figure 3(a)) of the second mode can also be detected from the JRA-25 data. Furthermore, composite analysis is performed on the East Asian winter SAT for the period of 1997-2011 and 1979-1996 by using the two reanalysis datasets. As shown in Figure 4, the SAT anomalous pattern over East Asia displays a notable "south-positive-north-negative" dipole structure, resembling the spatial distribution of EOF2 shown in Figure 2(a). These results further confirm that there is a significant interdecadal shift in winter SAT variations over East Asia in the late 1990s.

Recent studies also show that other meteorological elements in climate system also had similar interdecadal variations in the late 1990s. For example, the center Arctic pattern of the Arctic summer surface wind field variability also experienced a transition from cyclonic to anticyclonic surface wind anomalies at around 1996/1997 [38]. And the atmospheric vorticity index over the center Arctic Ocean to the north of the Laptev Sea showed a negative trend after 1990 and became negative after 1996 [39]. The summer precipitation over Eastern China switched from a meridional triple pattern to a dipole pattern around the late 1990s as well [40]. All of the above are dynamically consistent with our results here.

\section{Atmospheric circulation anomalies associated with the interdecadal variation of East Asian winter SAT}

In order to explore the characteristics of atmospheric circulation variability associated with the interdecadal variation of East Asian winter SAT in the late 1990s, a composite analysis is performed. Based on the Figure 2(b), we focus our attention on two periods: 1997-2011 and 1979-1996. Differences in atmospheric circulation between the former and latter periods are presented, as shown in Figure 5(a)-(c). All the atmospheric circulation variables are derived from the NCEP/NCAR reanalysis data. The results document that significantly positive SLP anomalies occur in northern Eurasia, and there is an anomalous center close to the Kara Sea (Figure 5(a)), which makes northerlies strengthened, leading to the southward expansion of the cold air from high latitudes and negative SAT anomalies over Northeast Asia (not shown). The 500-hPa geopotential height differences exhibit a clear wave-train pattern, with anticyclonic anomalies over northern Eurasia and cyclonic anomalies over the Baikal Lake,
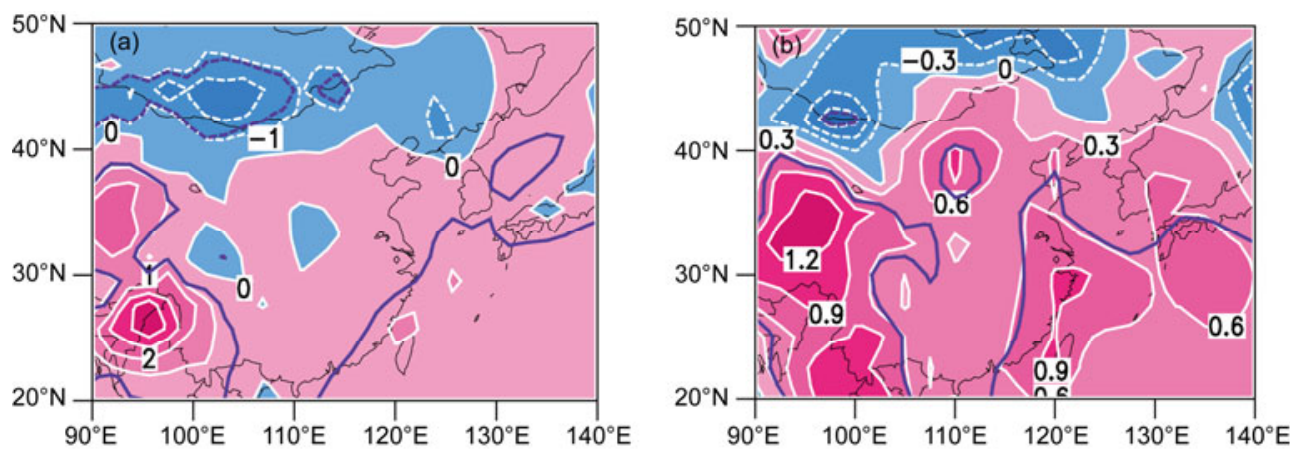

Figure 4 Differences in East Asian winter SAT between 1997-2011 and 1979-1996, (a) derived from the NECP/NCAR reanalysis data, (b) derived from the JRA-25 reanalysis data. Purple line presents differences exceeding the $95 \%$ significant tests. 

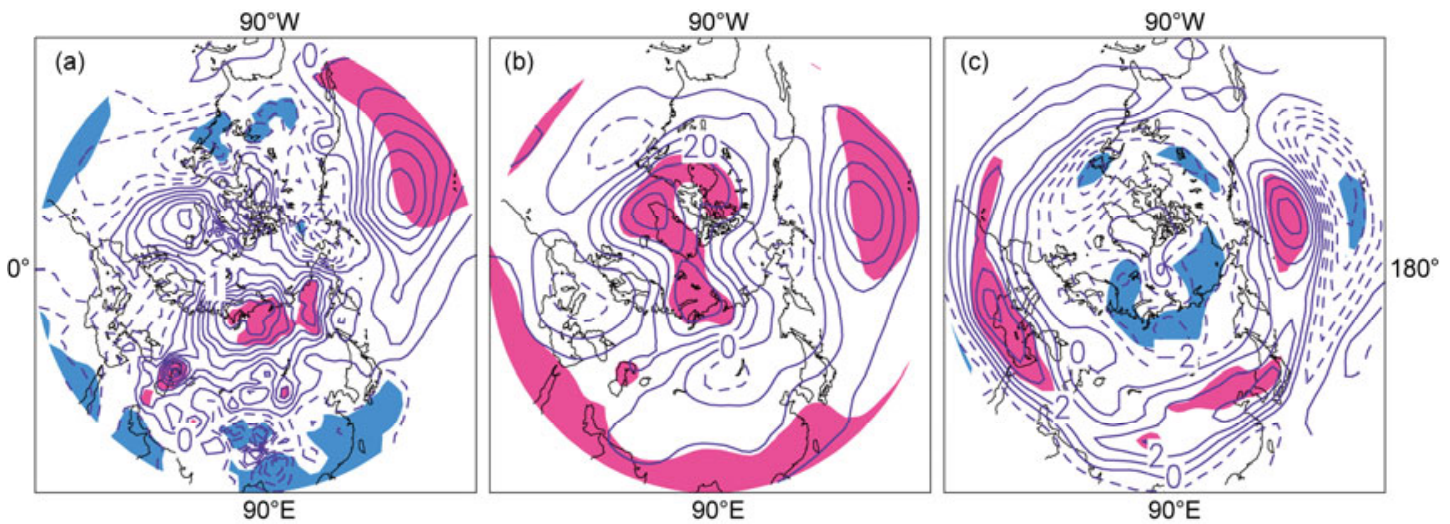

Figure 5 Differences between 1997-2011 and 1979-1996 in winter (a) mean SLP (hPa); (b) 500-hPa heights (gpm); (c) 200-hPa zonal wind (m/s). The shaded areas indicate differences exceeding the $95 \%$ significant tests.

respectively (Figure 5(b)). These would result in strengthened northerly anomalies and lower SAT over northern East Asia. Compared to the period of 1979-1996, the upper-level East Asian jet stream (EAJS) tends to shift northwards and become stronger during the period of 1997-2011, which obstructs the southward expansion of cold air, leading to positive SAT anomalies over the low latitudes of East Asia. It is known from our analyses that the circulation anomalies over the mid-high latitudes of Eurasia are all favorable for the interdecadal variation of East Asian winter SAT in the late 1990s.

\section{Possible causes of the interdecadal shift of East Asian winter SAT}

As mentioned in Section 3, the interdecadal shift of East Asian winter SAT in the late 1990s has a strong relationship with the atmosphere circulation anomalies over the midhigh latitudes of Eurasia and East Asia. Moreover, interdecadal variations of atmosphere circulation are a result of the interaction among many different factors, especially the external forcing factors [41]. For instance, the interdecadal variations of Arctic SIC and SST could cause interdecadal shifts of atmospheric circulation over local and the North Atlantic Ocean $[42,43]$. In order to investigate the possible causes of the interdecadal shift of East Asian winter SAT in the late 1990s, we analyze the interdecadal shift of SST and SIC in previous autumn in this section.

\subsection{SST anomalies in preceding autumn}

With characteristics of high thermal capacity and slow variation, ocean is the main driving factor for the interannual, interdecadal variability or even longer-term change of atmospheric circulation. Wang et al. [44] showed that although the extent and magnitude of SST anomalies were not at a large degree, they were still important trigger factors for climate variability. Thereby, it is necessary to explore the possible effects of previous autumn SST anomalies on the interdecadal shift of East Asian winter SAT in the late 1990s.

Figure 6 shows the differences of autumn mean SST between 1997-2011 and 1979-1996. It is evident that there are significantly positive SST anomalies in the Arctic Ocean, the North Indian Ocean, the North Atlantic Ocean and the western North Pacific Ocean, implying that interdecadal shifts in SST in those areas consistently occurred. To extract dominant modes in the North Atlantic Ocean SST variability, an EOF analysis is applied to previous autumn monthly mean SST in the domain $0^{\circ}-60^{\circ} \mathrm{N}$ and $80^{\circ} \mathrm{W}-0^{\circ} \mathrm{E}$ during the period 1979-2011. The leading mode exhibits a uniform feature with positive anomalies in the North Atlantic Ocean (Figure 7(a)), and shows a great similarity to the spatial distribution shown in Figure 6, indicating consistent warming or cooling in this area. Correspondingly, an apparent interdecadal shift of the standard time series could be observed in the late 1990s (Figure 7(b)). It also demonstrates the dominance of the leading SST mode with a mean negative phase until 1996, followed by a mean positive phase since 1997. A further analysis indicates that the cumulative deviation time series of the leading SST mode (not shown) reaches its lowest value in the winter of 1996/1997, implying

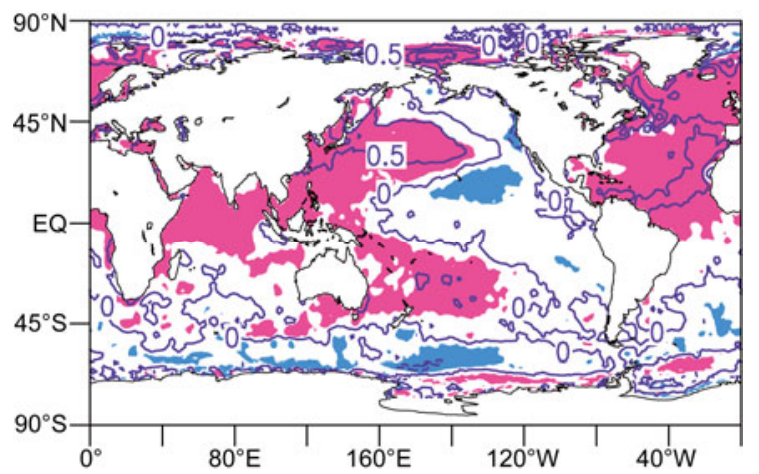

Figure 6 Differences in autumn mean SST (K) between 1997-2011 and 1979-1996. Shading areas indicate differences exceeding the $95 \%$ significant tests. 

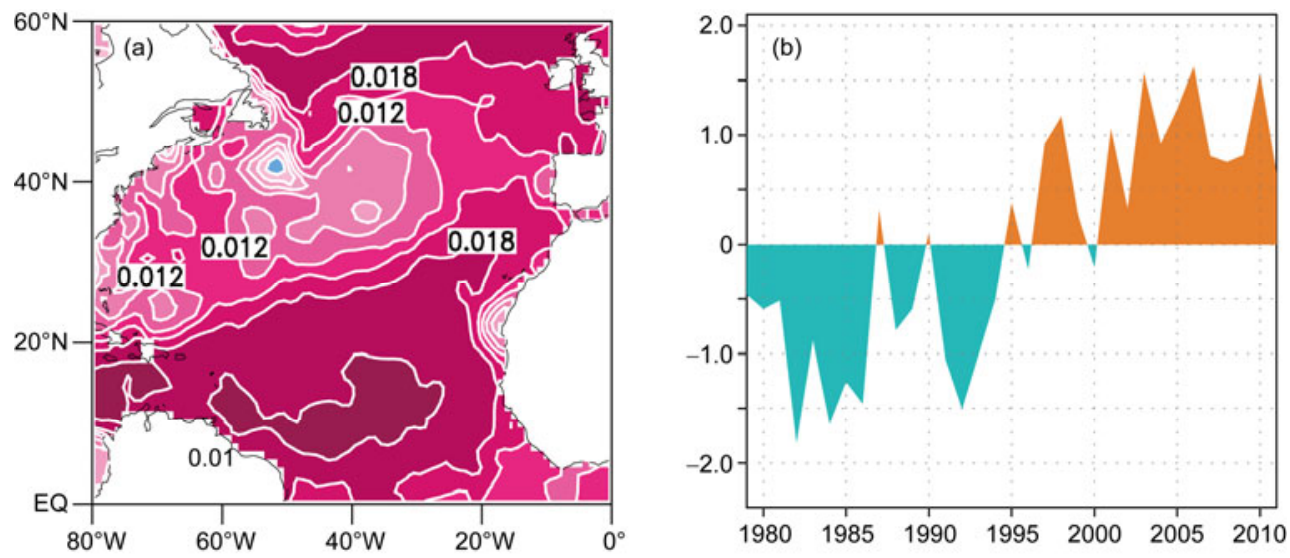

Figure 7 The spatial distribution (a) and standardized time series (b) of the leading EOF mode of the autumn mean SST in the North Atlantic Ocean for 1979-2011.

that this year may be a turning point of abrupt change. Likewise, very similar results analyzed by the M-K test method are also observed (not shown). Combined with Figure 7(a), we can find that the preceding autumn mean SST in the North Atlantic Ocean was mainly colder than the normal before the winter of 1996/1997, then turned to warmer after that. Additionally, by the same way to analyze SST over the Arctic Ocean, the North Indian Ocean and the western North Pacific Ocean, we also find that the turning points of SST interdecadal variations in these areas consistently occurred around the late 1990s, which were in agreement with the result of Xiao and $\mathrm{Li}$ [45].

Previous studies have pointed out that a successive autumn-winter positive SST anomalies in the East Arctic Ocean and the Greenland-Barents-Kara Seas (particularly in the northern North Atlantic Ocean) caused winter positive SLP anomalies over northern Eurasia and the northern North Atlantic Ocean. And these SST anomalies led to a strengthened SH and weakened westerlies over the mid-high latitudes of Eurasia. The weakened westerlies favored cold air's breaking out southward from high latitudes, leading to negative SAT anomalies over the mid-high latitudes of East Asia [18]. An upper wave-train-like anomaly chain across the North Atlantic Ocean and coastal Europe was triggered by the early winter western North Atlantic SST anomalies, resulting in a positive geopotential height anomaly over the Urals, then affecting the East Asian winter SAT [46]. Meanwhile, the Atlantic Multidecadal Oscillation (AMO) also had a notable modulating role to the interdecadal variability of East Asian winter monsoon climate, indicating that the northwest Atlantic SST anomalies played an important role in the interdecadal variations of East Asian winter SAT [47]. Moreover, positive SST anomalies in the western North Pacific Ocean during early autumn could enlarge the zonal heat difference between land and sea, then strengthened the northerly, favoring cold air's breaking out southward from high latitudes. On the contrary, positive SST anomalies in the North Indian Ocean resulted in obstructing cold air's breaking out southward from high latitudes. Such a discrepancy is reasonable, because the positive SST anomalies in the North Indian Ocean could enhance the meridional heat difference between the land and the sea, thus strengthened the westerlies. In recent decades, the combining effects of the positive SST anomalies in North Indian Ocean and the western North Pacific Ocean are beneficial to the emergence of East Asian SAT distribution pattern, that is positive in the south and negative in the north. From the conclusion mentioned above, it can be surmised that the previous autumn SST anomalies in the Arctic Ocean, the North Atlantic Ocean, the North Indian Ocean and the western North Pacific Ocean might cause a large impact on the interdecadal shift of East Asian winter SAT in the late 1990s.

\subsection{Arctic SIC anomalies in preceding autumn}

As one of the important parts and sensitive factors in the climatic system, the Arctic SIC also plays a role in influencing East Asian climate [18,48,49]. Thus, we will analyze the possible reasons why the Arctic SIC anomalies in preceding autumn affect the interdecadal shift of East Asian winter SAT in the late 1990s.

The spatial distribution of previous autumn Arctic SIC differences and its $t$-test between 1997-2011 and 19791996 are shown in Figure 8. It is found that significant negative SIC anomalies are mainly in the eastern Arctic Ocean, Arctic Eurasian marginal seas, the Beaufort Sea, etc. In order to extract dominant patterns of the Arctic SIC variability, an EOF analysis is applied to autumn monthly mean SIC over the Arctic during the period 1979-2011. The spatial distribution of the leading SIC mode is characterized by consistent variation (Figure 9(a)), which is similar to SIC differences shown in Figure 8(a), but with opposite sign, indicating consistent increasing or decreasing of SIC in the Arctic Ocean. The corresponding time series has an obvious interdecadal variation in the late 1990s (Figure 9(b)). It shows the dominance of the leading SIC mode with a mean 

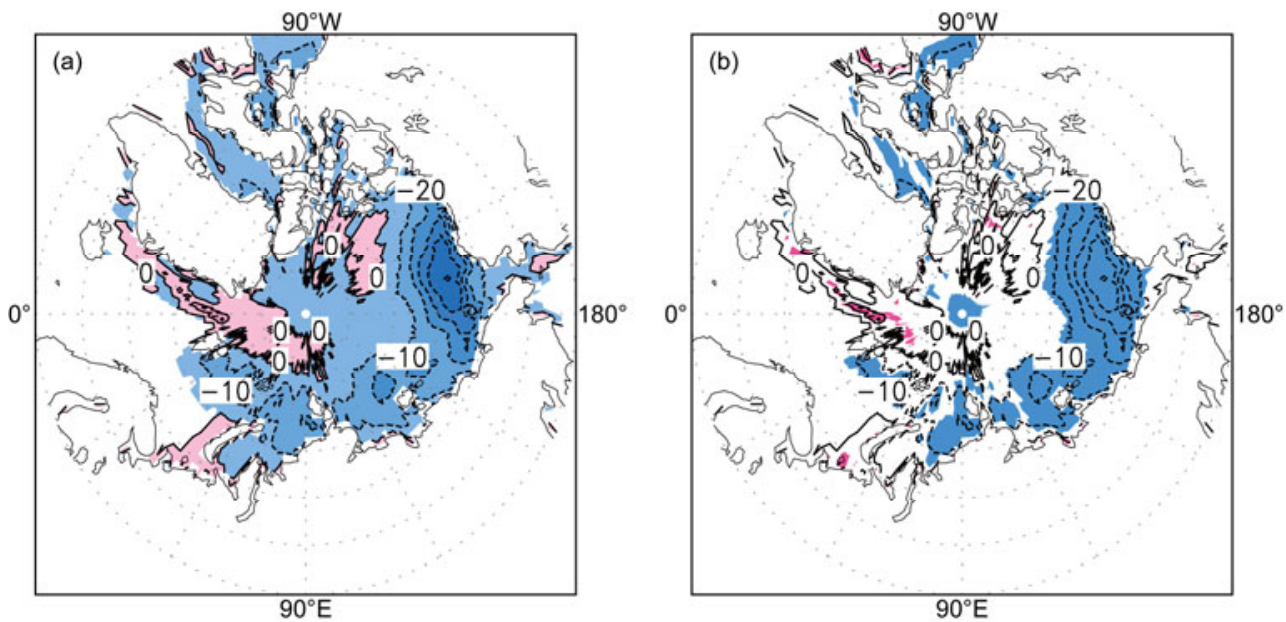

Figure 8 (a) Differences in autumn mean SIC between 1997-2011 and 1979-1996, (b) as in (a), but for the $t$-test, shaded areas in (b) indicate the differences exceeding the $95 \%$ significant tests.
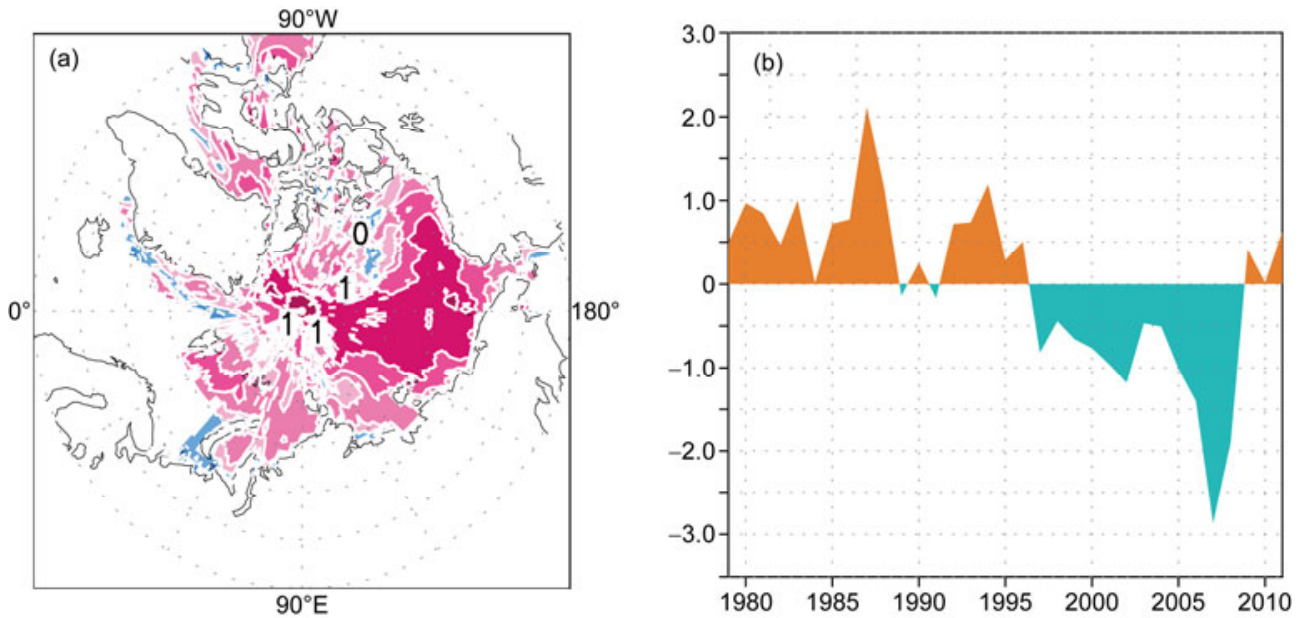

Figure 9 Same as in Figure 7, but for the SIC over the Arctic Ocean.

negative phase until 1996, followed by a mean positive phase since 1997, implying that the winter of 1996/1997 may be a turning point of abrupt change. Likewise, very similar results demonstrated by $\mathrm{M}-\mathrm{K}$ test, moving $t$-test and cumulative deviation were also observed (not shown). And the result is also supported by $\mathrm{Wu}$ et al. [41]. It means that the preceding autumn Arctic SIC indeed appeared a remarkable interdecadal variation in this period, whose turning point is the same as the East Asian winter SAT. The above results suggest that the interdecadal shift of previous autumn Arctic SIC is correlated with the interdecadal variation of East Asian winter SAT in the late 1990s.

According to the mechanism proposed to explain the association between autumn-winter SIC and the East Asian winter SAT [18], we could find that the autumn deceased SIC in the Arctic (particularly in the East Arctic Ocean and the Barents-Kara Seas) results in positive SAT anomalies over the Arctic, which weakens atmospheric thermal gradients between the Arctic and the mid-high latitudes of Eura- sia, leading to the weakened westerlies over northern Eurasia and the strengthened meridional winds. The strengthened meridional winds favor cold air's breaking out southward from high latitudes, leading to negative SAT anomalies over northern East Asia and positive SAT anomalies over southern East Asia. Furthermore, the remote response in winter is regarded as a stationary Rossby wave generated thermally through an anomalous turbulent heat fluxes as a result of anomalous ice-cover over the Barents-Kara Seas in preceding autumn, which tends to induce an amplification of the $\mathrm{SH}$, then causes colder conditions over East Asia [17]. Therefore, it could be assumed that the interdecadal shift of East Asian winter SAT in the late 1990s may result from the significant decrease of the previous autumn Arctic SIC. In addition, it is noteworthy that winter SIC variability also has an important influence on the East Asian winter SAT. For example, due to a weak SST gradient in the Barents Sea, atmospheric baroclinicity is lower in the light ice years, which prevents cyclones from moving eastward. And this 
could lead to fewer cyclones and anticyclone anomalies occupy over the Siberian coast, hence tending to be colder in winter over East Asia [50]. Additionally, the heavy (light) ice-cover over the Barents-Kara Seas in winter resulted in positive (negative) SLP anomalies, and weakened (strengthened) the cold high pressure over Asia as well as SH. At the same time, the North Pacific SLP would also increase (decrease). As a result, the East Asian winter monsoon weakened (enhanced), which led to the East Asian winter SAT anomalies finally [16].

\section{Discussion and conclusions}

(1) It is indicated by the NCEP/NCAR and JRA-25 reanalysis data that the dominant modes of East Asian winter SAT are highly consistent. The leading mode depicts a pan-East Asia SAT variation. The second mode describes a meridional dipole between the northern and southern parts of East Asia, with a turning point around 1996/1997. And it exhibits a notable interdecadal shift in the late 1990s, namely, the northern (southern) part of East Asia tends to be cooler (warmer) during the recent decades.

(2) Differences in the winter mean SLP between 19972011 and 1979-1996 show a negative (positive) anomaly over southern (northern) Eurasia. And the 500-hPa height differences exhibit a clear wave-train pattern, with significant anticyclonic anomalies over northern Eurasia and cyclonic anomalies over the Baikal Lake. In addition, compared to the period 1979-1996, the EAJS tends to be intensified and located northward during the period 1997-2011. It is thus clear that the interdecadal shift of East Asia winter SAT is likely coupled with the changes of the large-scale atmospheric circulation in the late 1990s.

(3) Additionally, the preceding autumn SST and SIC differences between 1997-2011 and 1979-1996 show positive SST anomalies over the Arctic Ocean, the North Atlantic Ocean, the North Indian Ocean and the western North Pacific Ocean, and negative SIC anomalies over the northern Eurasia marginal seas and the Beaufort Sea.

Further analysis indicates that the interdecadal shifts of SST over the North Atlantic Ocean and SIC over the Arctic are both well coherent with that of the winter SAT over East Asia. Therefore, the interdecadal shift of East Asian winter SAT may be related to the changes in SST over the North Atlantic Ocean and SIC over the Arctic in the late 1990s. Additionally, previous autumn Eurasian snow cover may also have substantial effect on the East Asian winter SAT. And its influence is intimately related to the interaction between troposphere and stratosphere [15]. As the Eurasian snow cover has not experienced apparent changes in the late 1990s, it is difficult for us to explain how the Eurasian snow cover influenced the interdecadal shift of East Asian winter SAT. In addition, human activities may also be a possible reason for the interdecadal shift of East Asian winter SAT in the late 1990s. For instance, it can cause the increase of greenhouse gases, leading to enhancement of global warming, which particularly increases the SAT over the Arctic gives rise to light SIC, and in the result makes the East Asian winter SAT down. However, the process that human activities influence the East Asian winter SAT is very complex, so it is hard to directly detect and distinguish the magnitude of the influence by limited observation data.

In this study, conclusions are limited to the results of statistical analysis. Apparently, the mechanisms responsible for the effects of preceding autumn SICs and SSTs on winter SAT over East Asia and their relative roles deserve further investigation via using observations and simulation experiments in the future.

We thank NOAA and JRA-25 for providing the reanalysis data. Thanks particularly go to the three anonymous reviewers for their constructive and insightful comments. This work was supported by the National Natural Science Foundation of China (41221064 and 40875052), the Calling Project of China (GYHY200906017), the Ship Channel in Arctic (201205007-7) and the Basic Research Foundation of CAMS (2010Z003).

1 Li Y, Lu R Y, He J H. Several climate factors influencing the winter temperature over China (in Chinese). Chin J Atmos Sci, 2007, 31: 505-514

2 Chen P Y, Ni Y Q, Yin Y H. Diagnostic study on the impact of the global sea surface temperature anomalies on the winter temperature anomalies in East China in the past 50 years (in Chinese). J Trop Meteorol, 2001, 17: 371-380

3 Wu B Y, Bian L G, Zhang R H. Effects of the winter AO and the Arctic sea ice variations on climate variation over East Asia (in Chinese). J Polar Res, 2004, 16: 211-220

4 Saito K, Cohen J. The potential role of snow cover in forcing interannual variability of the major Northern Hemisphere mode. Geophys Res Lett, 2003, 50: 1302

5 Guo Q Y. Relationship between the variations of East Asian Winter Monsoon and temperature anomalies in China (in Chinese). J Appl Meteorol Sci, 1994, 5: 218-225

6 Ding Y H. Buildup, air mass transformation and propagation of Siberian High and its relations to cold surge in East Asia. Meteorol Atmos Phys, 1990, 44: 281-292

7 Mao R, Gong D Y, Fang Q M. Influences of the East Asian jet stream on winter climate in China (in Chinese). J Appl Meteorol Sci, 2007, 18: $137-146$

8 Chen W, Lan X Q, Wang L, et al. The combined effects of the ENSO and the Arctic Oscillation on the winter climate anomalies in East Asia. Chin Sci Bull, 2013, 58: 1355-1362

9 Suo L L, Tan B K, Huang J Y. Further exploration on causes of temperature anomalies associated with the abnormal northern annular mode. Chin Sci Bull, 2009, 54: 2101-2106

10 Wu B Y, Huang R H. Effects of the Extremes in the North Atlantic Oscillation on East Asia winter monsoon (in Chinese). Trans Atmos Sci, 1999, 23: 641-651

11 Zuo J Q, Li Wi Q, Ren H L, et al. Change of the relationship between spring NAO and East Asian Summer Monsoon and its possible mechanism. Chin J Geophys, 2012, 55: 23-34

12 Liu Y Y, Chen W. Variability of the Eurasian teleconnection pattern in the Northern Hemisphere winter and its influences on the climate in China (in Chinese). Chin J Atmos Sci, 2012, 36: 423-432

13 Wu B Y, Zhang R H, D'Arrigo R. Distinct modes of the East Asian winter monsoon. Mon Weather Rev, 2006, 134: 2165-2179

14 Li S, Bates G T. Influence of the Atlantic multidecadal oscillation on the winter climate of East China. Adv Atmos Sci, 2007, 24: 126-135

15 Barnett T P, Dumenil L U, Schlcse E, et al. The effect of Eurasian 
snow cover on regional and global climate variations. J Atmos Sci, 1989, 46: 661-685

16 Wu B Y, Huang R H, Gao D Y. The impact of variation of sea-ice extent in the Kara Sea and the Barents Sea in winter on the winter monsoon over East Asia (in Chinese). Chin J Atmos Sci, 1999, 23: 267-275

17 Honda M, Cohen J L, Yamane S. Influence of low Arctic Sea-SIC minima on anomalously cold Eurasian winters. Geophys Res Lett, 2009, 36: L08707

18 Wu B Y, Su J Z, Zhang R H. Effects of autumn-winter Arctic sea ice on winter Siberian High. Chin Sci Bull, 2011, 56: 3220-3228

19 Wallace J M, Zhang Y, Bajuk L. Interpretation of interdecadal trends in Northern Hemisphere surface air temperature. J Clim, 1996, 9: 249-259

20 Kang L H, Chen W, Wei K. The interdecadal variation of winter temperature in China and its relation to the anomalies in atmospheric general circulation (in Chinese). Clim Environ, 2006, 11: 330-339

21 Zhu Y M, Yang X Q. Relationships between Pacific deeadal oscillation (PDO) and climate variabilities (in Chinese). Acta Meteorol Sin, 2003, 61: 641-654

$22 \mathrm{Ju}$ J H, Ren J Z, Lv J M. Effect of interdecadal variation of Arctic Oscillation on temperature increasing in north of East Asian winter (in Chinese). Plateau Meteorol, 2004, 23: 429-434

23 Hurrell J W. Influence of variations in extra-tropical wintertime teleconnections on northern hemisphere. Geophys Res Lett, 1996, 23: 665-668

24 Zhou B T, Wang H J. Interdecadal change in the connection between Hadley circulation and winter temperature in East Asia. Adv Atmos Sci, 2008, 25: 24-30

25 Gong D Y, Wang S W. Variability of the Winter Zonal Index and its association with the Northern Hemisphere temperature changes (in Chinese). J Trop Meteorol, 2002, 18: 104-110

26 Shi N. Features of the East Asian Winter Monsoon intensity on multiple time scale in recent 40 years and their relation to climate (in Chinese). J Appl Meteorol Sci, 1996, 7: 175-182

$27 \mathrm{Ju}$ J H, Ren J Z. Possible impact of winter North Pacific surface sea temperature fields on surface air temperature (in Chinese). Sci Meteorol Sin, 2005, 25: 18-25

28 Zhao Z C, Wang S W, Xu Y, et al. Attribution of the 20th century climate warming in China (in Chinese). Clim Environ, 2005, 10: 809-817

29 Qian W H, Lu B, Liang H Y. Changes in fossil-fuel carbon emissions in response to interannual and interdecadal temperature variability. Chin Sci Bull, 2011, 56: 319-324

30 Kalnay E, Kanamitsu M, Kistler R, et al. The NCEP/NCAR 40-year reanalyses project. Bull Amer Meteorol Soc, 1996, 77: 437-472

31 Onogi K, Tsutsui J, Koide H, et al. The JRA-25 reanalysis. J Meteorol Soc Jpn, 2007, 85: 369-432

32 Wu B Y, Wang J. Winter Arctic Oscillation, Siberian High and East Asian winter monsoon. Geophys Res Lett, 2002, 19: 297-320

33 Rayner N A, Parker D E, Horton E B, et al. Global analyses of sea surface temperature, sea ice, and night marine air temperature since the late nineteenth century. J Geophys Res, 2003, 108: 4407
34 Zhao T B, Fu Z B. Applicability evaluation of surface air temperature from several reanalysis datasets in China (in Chinese). Plateau Meteorol, 2009, 28: 594-606

35 China Climate Change Group. China Climate Change Country Study (in Chinese). Beijing: Tsinghua University Press, 2000. 20-23

36 North G R, Bell T L, Cahalan R F, et al. Sampling errors in the estimation of empirical orthogonal functions. Mon Wea Rev, 1982, 110: 699-706

37 He S P. Reduction of the East Asian winter monsoon interannual variability after the mid-1980s and possible cause. Chin Sci Bull, 2013, 58: 1331-1338

38 Wu, B Y, Overland J, D'Arrigo R. Anomalous Arctic surface wind patterns and their impacts on September sea ice minima and trend. Tellus A, 2012, 64: 1-16

39 Polyakov I, Johnson M. Arctic decadal and interdecadal variability. Geophys Res Lett, 2000, 27: 4097-4100

40 Huang R H, Liu Y, Feng T. Interdecadal change of summer precipitation over Eastern China around the late-1990s and associated circulation anomalies, internal dynamical causes. Chin Sci Bull, 2013, 58: 1339-1349

41 Wu B Y, Wang J, Walsh J. Possible feedback of winter sea ice in the Greenland and the Barents Sea on the local atmosphere. Mon Weather Rev, 2004, 132: 1868-1876

42 Mysak L A, Manak D K, Marsden R F. Sea-ice anomalies observed in the Greenland and Labrador Seas during 1901-1984 and their relation to an interdecadal Arctic climate cycle. Clim Dyn, 1990, 5: $111-133$

43 Mysak, L A, Venegas S A. Decadal climate oscillation in the Arctic: A new feedback loop for atmosphere-ice-ocean interactions. Geophys Res Lett, 1998, 25: 3607-3610

44 Wang Q Q, Qian Y F. Numerical study of influence on rainfall of 1991 Pacific SST Anomaly (in Chinese). Trans Atmos Sci, 1995, 18: 200-205

45 Xiao D, Li J P. Main decadal abrupt changes and decadal modes in global sea surface temperature field (in Chinese). Chin J Atmos Sci, 2007, 5: 839-854

46 Li S L. Impact of northwest Atlantic SST anomalies on the circulation over the Ural Mountains during early winter. J Meteorol Soc Jpn, 2004, 82: 971-988

47 Wang Y, Li S, Luo D. Seasonal response of Asian monsoonal climate to the Atlantic Multidecadal Oscillation. J Geophys Res, 2009, 114: D02112

48 Petoukhov V, Semenov V A. A link between reduced Barents-Kara sea ice and cold winter extremes over northern continents. Geophys Res Lett, 2010, 115: D21111

49 Wu Q G, Zhang X D. Observed forcing-feedback processes between Northern Hemisphere atmospheric circulation and Arctic sea ice coverage. J Geophys Res, 2010, 115: D14119

50 Cohen J L, Hori M E, Takaya K. The Role of Barents Sea Ice in the Wintertime cyclone track and emergence of a Warm-Arctic ColdSiberian Anomaly. Amer Meteorol Soc, 2012, 25: 2561-2568

Open Access This article is distributed under the terms of the Creative Commons Attribution License which permits any use, distribution, and reproduction in any medium, provided the original author(s) and source are credited. 